\title{
A comparative assessment of the glucose monitor (SD Codefree) and auto analyzer (BT-3000) in measuring blood glucose concentration among diabetic patients
}

\author{
Osman Nabayire Kanwugu', Gideon Kofi Helegbe ${ }^{1 *}$, Paul Armah Aryee ${ }^{2}$, Nathaniel Amigamsa Akontatiba ${ }^{3}$, \\ Jacob Ankrah", Nsoh Godwin Anabire ${ }^{1}$, Frank Anaba ${ }^{1}$ and Benjamin Ahenkora ${ }^{5}$
}

\begin{abstract}
Objective: The aim of this study was to determine how well the measurements from a glucometer (SD Codefree) correlated with those from a standard auto analyser (BT-3000) using blood samples from diabetic and non-diabetic patients at the Bolgatanga Regional Hospital in Ghana. A cross-sectional study was conducted with a total of 150 randomly selected patients; 100 diabetic patients (4 type 1 and 96 type II) and 50 non diabetic patients. Ante-cubital venous and finger pricked blood samples were obtained from the patients following standard procedures, and blood glucose concentrations were determined using the two methods respectively.

Results: Data generated was entered and analysed using SPSS version 20. The mean glucose concentration for the diabetic patients $(n=100)$ using the glucometer were not significantly different from that of the auto analyser $(10.16 \pm 3.708 \mathrm{mmol} / \mathrm{L}$ vs. $9.458 \pm 3.204 \mathrm{mmol} / \mathrm{L}, \mathrm{P}=0.154)$, though the glucometer generally overestimated the glucose concentration. Similarly, readings for non-diabetics were comparable between the two methods $(5.286 \pm 0.477 \mathrm{mmol} / \mathrm{L}$ vs. $5.092 \pm 0.525 \mathrm{mmol} / \mathrm{L}, \mathrm{p}=0.057)$. The correlation between the two methods was good and highly significant $(r=0.862, p<0.001)$ with both methods depicting high sensitivity and specificity in measuring blood glucose levels among diabetics as indicated by the ROC curve.
\end{abstract}

Keywords: Diabetes mellitus, Hyperglycaemia, Glucometer, Auto analyzer

\section{Introduction}

Diabetes mellitus is a group of metabolic diseases characterized by elevated blood glucose concentration (hyperglycaemia) resulting from either defects in insulin secretion by the pancreas, insulin action or both [1] While type-I DM occurs mostly in individuals less than 18 years of age and accounts for only $5-10 \%$ diabetics, type-II DM has a common occurrence in people over 40 years of age and accounts for $90-95 \%$ of individuals with diabetes [1-3]. Diabetes mellitus is a cause of

\footnotetext{
*Correspondence: ghelegbe@uds.edu.gh

${ }^{1}$ Department of Biochemistry \& Molecular Medicine, School of Medicine and Health Sciences, University for Development Studies, P. O. BoxTL 1883, Tamale, Ghana

Full list of author information is available at the end of the article
}

morbidity, disability and mortality worldwide. Diabetichyperglycaemia is often marked by polyuria, polydipsia, weight loss and sometimes polyphagia and blurred vision [4]. It has been estimated that the total number of diabetics worldwide will rise from 171 million as at 2000 to 366 million in 2030 with more than $85 \%$ of them living in low and middle income countries [5].

Increasingly, glycaemic control is being recognized as a priority in the treatment of critically ill diabetic patients as it has helped to significantly reduce mortality and morbidity [6,7]. The acquisition of information about blood glucose concentration is an important parameter for the establishment of much diagnostic as well as vital therapy [2]. Glucometers are devices developed to measure glycemia of capillary blood obtained through finger 
or heel puncture using a lancet or hypodermic needle. They are automatic, fast and easy to use and determine the blood glucose concentration mostly by means of either photometric or electrochemical reactions [8]. Currently, many diabetics achieve SMBG in two general ways of measuring their blood glucose; the glucometer and the laboratory-based chemistry auto analyser. Although the latter method is perceived as more reliable and accurate, the use of the glucometer is rather preferred because it is portable and convenient to use. However, for effective SMBG it is imperative to have reliable and accurate measure of blood glucose level. In the recent years, conflicting results have been reported with regard to the accuracy of these devices [15]. Currently in Ghana, however, litthe to no literature is available on the accuracy of these devices. Meanwhile, SD codefree glucometer is one of the main glucometers used in Ghana including the Bolgatanga Regional Hospital. This calls to question the need to ascertain the accuracy and reliability of the glucometer in comparison with the standard laboratory method. This current study is an attempt to explore the accuracy of one of the many brands of glucometers that have flooded the Ghanaian market.

\section{Main text \\ Methods \\ Study design}

The study design was cross-sectional comprising of a total of 150 randomly selected patients; 100 diabetics (4 type 1 and 96 type II) and 50 non diabetic. The sample size was determined with Cochran's sample size determination formula using diabetes prevalence of $6.5 \%$ and 95\% confidence interval.

\section{Study area}

The study was carried out in Bolgatanga, the capital town of the Upper East Region of Ghana and co-terminus with the Bolgatanga Municipal Assembly. It is situated at the centre of the region and to the north-eastern part of Ghana. It has a total land area of $729 \mathrm{sq} \mathrm{km}$ [9]. The Municipal has a total of 1698 reported cases of DM [10].

\section{Subject recruitment}

Diabetic patients (as stated in their folders) attending the diabetic clinic of the Bolgatanga Regional Hospital were randomly selected for the study. In addition, non-diabetic patients (per their medical records) attending the outpatients' department (OPD) and eye clinic of the hospital were also randomly recruited as controls. At each department visited, the study and its significance were explained to all patients and medical records of all who volunteered to be part were reviewed, those with other known metabolic disorders were excluded from the study.

\section{Data/sample collection}

After consent was obtained from participants, sociodemographic information including sex, age and type of $\mathrm{DM}$, were collected by the authors with the aid of questionnaires during the data collection process. Those involved in the questionnaire administration were given a 1-day training, and questionnaire was pre-tested. Blood samples were collected by a trained medical laboratory scientist from the ante cubital vein and capillary of fingers for the reference glucose oxidase method and glucometer measurements respectively, after an overnight fast $(8-14 \mathrm{~h})$, and following standard procedures as described by [11].

\section{Measurement of glucose level using the glucometer}

Glucose level in capillary blood was measured with the glucometer (SD Codefree) using standard procedures described by the manufacturer.

\section{Measurement of glucose level using the auto analyser}

Glucose level in venous blood was also measured with the auto analyser (BT-3000) following standard procedures described by the manufacturer.

\section{Data analysis}

The data collected from the study was analysed using SPSS version 20 and results presented as mean \pm standard deviation. The comparison of the mean values from the two methods was done using independent $t$ test at a 95\% confidence interval and the differences were considered statistically significant if $\mathrm{p}<0.05$ (Additional file 1).

\section{Results}

The blood glucose level of both diabetic and non-diabetic patients enrolled in this study was determined simultaneously with the glucometer (SD-Codefree) and auto analyser (BT-3000) in the laboratory of the Bolgatanga regional hospital. Results obtained did not show any significant statistical difference between blood glucose readings using both methods in diabetics and non-diabetics alike. However, it was notable that the glucometer tended to slightly over-estimate the measurements in all cases, averagely by $0.721 \mathrm{mmol} / \mathrm{L}$ in diabetics and $0.390 \mathrm{mmol} / \mathrm{L}$ in non-diabetics.

Among the diabetics (Table 1), the results showed no statistically significant difference $(\mathrm{p}=0.142)$ between glucose levels obtained with the glucometer $(10.135 \pm 3.708 \mathrm{mmol} / \mathrm{L})$ and the auto analyser $(9.411 \pm 3.224 \mathrm{mmol} / \mathrm{L})$. When glucose levels in this category was assessed according to age, the results did not show any statistically significant difference in the measurements between the glucometer and the auto analyser within patients aged $20-40(\mathrm{p}=0.680), 41-60$ 
Table 1 Mean concentration of glucose of diabetic patients

\begin{tabular}{|c|c|c|c|}
\hline & \multicolumn{2}{|c|}{ Mean glucose concentration $(\mathrm{mmol} / \mathrm{L}) \pm S D$} & \multirow[t]{2}{*}{$P$ value } \\
\hline & Glucometer $(n=100)$ & Auto analyzer $(n=100)$ & \\
\hline Mean FBS & $10.135 \pm 3.708$ & $9.411 \pm 3.224$ & 0.142 \\
\hline \multicolumn{4}{|l|}{ Age (years) } \\
\hline $20-40$ & $9.827 \pm 3.322$ & $9.288 \pm 2.683$ & 0.680 \\
\hline $41-60$ & $10.232 \pm 3.839$ & $9.434 \pm 3.264$ & 0.239 \\
\hline $61-80$ & $10.073 \pm 3.703$ & $9.441 \pm 3.404$ & 0.452 \\
\hline \multicolumn{4}{|l|}{ Sex } \\
\hline Female & $9.979 \pm 3.451$ & $9.310 \pm 3.396$ & 0.455 \\
\hline Male & $10.604 \pm 4.437$ & $9.711 \pm 2.973$ & 0.206 \\
\hline \multicolumn{4}{|c|}{ Type of diabetes } \\
\hline Type I & $8.525 \pm 2.886$ & $7.585 \pm 2.171$ & 0.621 \\
\hline Type II & $10.202 \pm 3.736$ & $9.487 \pm 3.246$ & 0.158 \\
\hline
\end{tabular}

Source: Field Survey Level of significance, $p<0.05$

$(\mathrm{p}=0.239)$ and $61-80(\mathrm{p}=0.452)$. Also, the difference in glucose levels obtained using the two methods among type I and type II diabetics were highly comparable ( $\mathrm{p}$ values of 0.621 and 0.158 respectively) even though measurements were slightly higher among type II diabetics.

In the non-diabetic group (Table 2), mean glucose level of $5.338 \pm 0.538 \mathrm{mmol} / \mathrm{L}$ was obtained with the glucometer while the auto analyser yielded a mean glucose level of $4.948 \pm 0.726 \mathrm{mmol} / \mathrm{L}$. Comparing the two means with $\mathrm{t}$-test yielded a p-value of 0.003 . In this same group, when blood glucose level was assessed according to age of patients, a significant difference was observed between the glucose level of patients aged 20-40 using the glucometer and the auto analyser $(5.450 \pm 0.544 \mathrm{mmol} / \mathrm{L}$ cf. $4.893 \pm 0.765 \mathrm{mmol} / \mathrm{L}, \mathrm{p}=0.004)$. However, among patients aged $41-60$, the results were not significantly different between measurements with the glucometer

Table 2 Mean glucose concentrations of non-diabetic patients $(n=50)$

\begin{tabular}{lccc}
\hline & \multicolumn{2}{c}{ Mean glucose concentration $(\mathbf{m m o l} / \mathbf{L}) \pm$ SD } & P value \\
\cline { 2 - 3 } & Glucometer $(\mathbf{n}=\mathbf{5 0})$ & Auto analyzer $(\mathbf{n}=\mathbf{5 0})$ & \\
\hline FBS & $5.338 \pm 0.538$ & $4.948 \pm 0.726$ & $0.003^{*}$ \\
Age (years) & & & \\
$20-40$ & $5.450 \pm 0.544$ & $4.893 \pm 0.765$ & $0.004^{*}$ \\
$41-60$ & $5.265 \pm 0.552$ & $4.978 \pm 0.674$ & 0.150 \\
$61-80$ & $4.975 \pm 0.150$ & $5.155 \pm 0.877$ & 0.711 \\
Sex & & & \\
Female & $5.503 \pm 0.458$ & $5.059 \pm 0.714$ & 0.162 \\
Male & $5.068 \pm 0.562$ & $4.767 \pm 0.727$ & 0.050 \\
\hline
\end{tabular}

Source: Field Survey * Statistically significant Level of significance, $p<0.05$ and that of the auto analyser $(5.265 \pm 0.552 \mathrm{mmol} / \mathrm{L}$ cf. $4.978 \pm 0.674 \mathrm{mmol} / \mathrm{L}, \mathrm{p}=0.150$ ), likewise that observed among patients aged 61-80 $(4.975 \pm 0.150 \mathrm{mmol} / \mathrm{L}$ cf. $5.155 \pm 0.877 \mathrm{mmol} / \mathrm{L}, \mathrm{p}=0.711)$. Similarly, results according to gender were not significantly different between measurements by the glucometer and the auto analyser among the female patients $(\mathrm{p}=0.050)$ as well as among the males $(\mathrm{p}=0.162)$.

All the results indicated a good and significant correlation between the glucometer and the auto analyser (Pearson correlation coefficient, $\mathrm{r}=0.862, \mathrm{p}<0.001$ ) as illustrated in Fig. 1. When the results were presented on a ROC curve, the area under the curve with regards to the glucometer was 0.962 while that of the auto analyser was 0.950 (Additional file 2).

\section{Discussion}

Self-monitoring of blood glucose (SMBG) using glucometers as an essential part of diabetes care has become prominent probably because it is a very practical and cost effective approach to diabetic self-care [2]. In recent years, conflicting results have been reported with regard to the accuracy of these devices [12-14]. The aim of this study was therefore to assess the efficiency of the glucometer by comparing it with the standard glucose oxidase/peroxidase colorimetric method used in measuring blood glucose concentration in the laboratory.

Much as the results between the two methods were not statistically significant irrespective of the diabetic status of patients, the glucometer tended to over-estimate

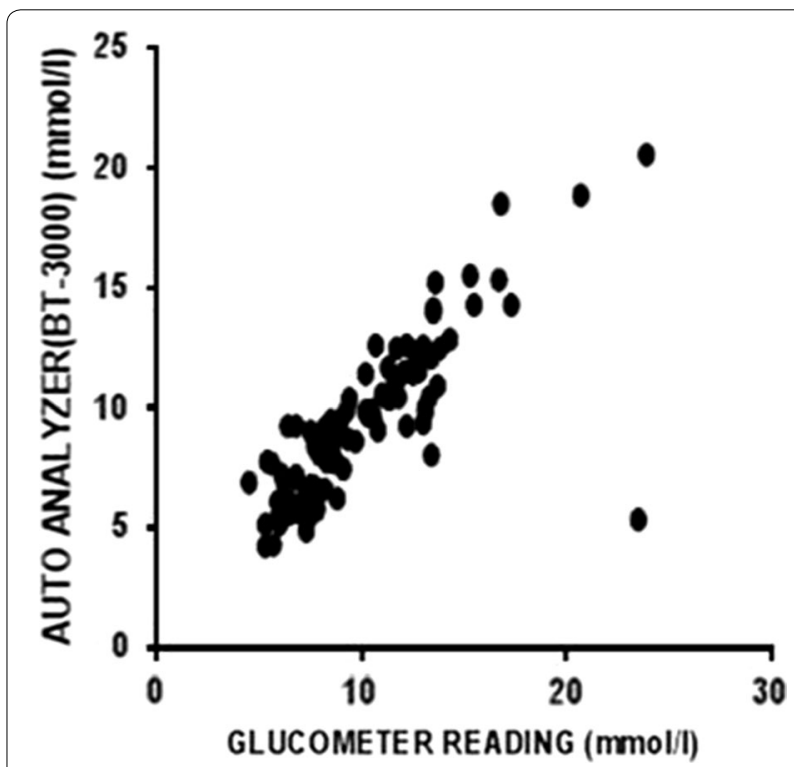

Fig. 1 Correlation between glucose levels measured using glucometer and BT-3000 auto analyser 
the measurements in almost all the cases. These results corroborate observations made in other studies [1517]. However, other studies conducted by [18] and [19] reported that the glucometer generally produced lower glucose readings though there was a good correlation between the glucometer and the auto analyser. The results above generally show that capillary blood glucose may not be reproducible as venous blood glucose concentration. Although the glucometers as well as the standards for comparisons in these studies are different in terms of brands, the underlining working principles [19] are the same and therefore make the results of this current study comparable to findings of these studies. In the body, blood glucose levels in the capillary differ from that in the veins. Venous plasma glucose level is the estimated glucose after utilization of glucose by tissues and depends on the extent of tissue extraction of glucose as well as effect of insulin, glucagon, growth hormone and cortisone [16]. The difference in blood glucose levels recorded by the glucometer and the auto analyser maybe accounted for partly by these factors mentioned above as well as changes in temperature and humidity and altitude [14]. The results from this study showed no influence of age, gender and type of DM on the glucose readings recorded by both methods.

The results show a near perfect correlation between glucose levels generated by the glucometer and the auto analyser. Thus, the glucometer used in this study is relatively accurate at measuring the glucose level of the patients and irrespective of their diabetes status. These findings correspond to those from studies conducted by [8] and [20] who found similar levels of correlation between the glucometer and auto analyser. However, in a similar study conducted in Uganda by [19] to determine the accuracy of three glucometer systems, only one (the system used by One Touch ${ }^{\mathrm{TM}}$, LifeScan Inc. and Milpitis) out of the three showed a good correlation with a secondary standard, pre-standardized by the laboratory based auto analyser. In contrast, a study conducted by [21] found a weak correlation $(r=0.275)$ between a glucometer and the laboratory based method in determining neonatal hypoglycaemia. In light of this, it would be wrong to assume that any brand of glucometer is accurate in its measurements until it has been standardised. Clearly, standardisation of glucometer brands against trusted methods is imperative to forestall obtaining results that may be spurious and could jeopardise the health of the patient.

A rather interesting finding observed in this current study is that the ROC curve showed the glucometer to be an even better method as indicated by the area under the curve than the auto analyser. The area under the ROC curve represents a measure of discrimination, thus, the ability of the test to classify correctly those with and without the disease. The closer the area under the ROC curve is to 1 , the more accurate the test [23]. Although over the years there has been advances in technology that has improved the glucometer, the variation in measurements that shows the glucometer to be more accurate in this study is most likely to be as a result of pre-analytical errors that may have occurred in the usage of the auto analyser. Nevertheless, despite the apparent accurate results observed this current study cannot be a basis to generalize for all glucometers on the market.

Overall, though the results of this study indicated that the glucometer can still be used for SMBG as part of diabetes management and care, it is, however, crucial that standardization of glucometer be given attention in policies geared toward management and control of diabetes since clearly, the accuracy of SMBG depends to a large extent on the instrument used as well as the user [22].

\section{Conclusion}

We conclude that the glucometer (SD Codefree) is as accurate as the auto analyser and therefore can be conveniently used as a rapid easy-to-use alternative. However, it is recommended that further studies be carried out using multiple glucometer brands.

\section{Limitation}

In this study, only the SD Codefree brand of glucometer was used and therefore the results cannot be generalized for all brands of glucometers found on the Ghanaian market.

\section{Additional files}

Additional file 1. Dataset: Data used for the analysis whose results are presented in this manuscript are carried out.

Additional file 2. ROC Curve: A graph presenting a ROC curve for both the glucometer and auto-analyzer.

\section{Abbreviations}

Cf: compared to; DM: diabetes mellitus; ROC: receiver operating characteristic; SMBG: self-monitoring of blood glucose; SPSS: Statistical Package for Social Sciences; Vs: versus.

\section{Author's contributions}

The idea of the study was conceived by GKH and PAA. ONK, GKH and JA contributed to the design of the study. ONK, NAA, GNA, BA and FA recruited the study participants, sought for written consent, administered questionnaires, and entered the data. ONK, NAA, FA, BA and JA performed the laboratory analysis. Analysis of the data was carried out by ONK, GKH and PAA. ONK, together with GKH and PAA drafted the manuscript. The study was supervised by GKH. All authors read and approved the final manuscript.

\section{Author details}

${ }^{1}$ Department of Biochemistry \& Molecular Medicine, School of Medicine and Health Sciences, University for Development Studies, P. O. Box TL 1883 Tamale, Ghana. ${ }^{2}$ Department of Community Nutrition, School of Allied Health 
Sciences, University for Development Studies, P. O. Box TL 1883, Tamale, Ghana. ${ }^{3}$ Department of Applied Chemistry \& Biochemistry, University for Development Studies, P. O. Box 24, Navrongo, Ghana. ${ }^{4}$ Department of Hematology, Tamale Central Hospital-Tamale, Tamale, Ghana. ${ }^{5}$ Bolgatanga Regional Hospital, Upper East, Bolgatanga, Ghana.

\section{Acknowledgements}

Our heartfelt appreciation and sincere thanks goes to the management of the Bolgatanga Regional Hospital, as well as the staff of the haematological unit for their inestimable efforts. We (authors) also extend our most sincere gratitude to the participants of this study for their patience and cooperation.

\section{Competing interests}

The authors declare that they have no competing interests.

\section{Availability of data and materials}

The datasets supporting the findings of this article are available in this manuscript and its additional files.

\section{Consent for publication}

Not applicable.

\section{Ethical approval and consent to participate}

Ethical approval of the research protocol was granted by the Ethics Committee of the School of Medicine and Health Sciences/School of Allied and Health Sciences, University for Development Studies. A written informed consent was obtained from each selected patient and control subject who volunteered to participate by way of signing or thumbprint. The benefit of the study was explained to them and they were also assured of confidentiality.

\section{Funding}

Not applicable.

\section{Publisher's Note}

Springer Nature remains neutral with regard to jurisdictional claims in published maps and institutional affiliations.

Received: 27 June 2017 Accepted: 31 August 2017

Published online: 06 September 2017

\section{References}

1. American Diabetes Association. Diagnosis and classification of diabetes mellitus. Diabetes Care. 2014;37(1):S81-90.

2. American Diabetes Association. Standards of medical care in diabetes. Diabetes Care. 2007;30(1):S4-41.

3. National Diabetes Education Program (NDEP). Overview of diabetes in children and adolescents. US Department of Health and Human Services; 2014.

4. American Diabetes Association. Diagnosis and classification of diabetes mellitus. Diabetes Care. 2014;37(1):S81-90
5. Rathmann W, Giani G. Global prevalence of diabetes: estimates for the year 2000 and projections for 2030. Diabetes Care. 2004;27(10):2568-9.

6. Van den Berghe G, Wouters PJ, Bouillon R, Weekers F, Verwaest P, Schetz M, Vlasselaers D, Ferdinande P, Lauwers P. Outcome benefit of intensive insulin therapy in the critically ill: insulin dose versus glycemic control. Crit Care Med. 2003;31(32):359-66.

7. Van den Berghe G, Wilmer A, Hermans G, Meersseman W, Wouters PJ, Milants I, Van Wijngaerden E, Bobbaers H, Bouillon R. Intensive insulin therapy in the medical ICU. N Engl J Med. 2006;354(5):449-61.

8. Louie RF, Tang Z, Sutton DV, Lee JH, Kost GJ. Point-of-care glucose testing: effects of critical care variables, influence of reference instruments, and a modular glucose meter design. Arch Pathol Lab Med. 2000;124(2):257-66.

9. Ghanadistricts.com. http://ghanadistricts.com/DistrictSublinks. aspx?s=3824\&dist|D=149. Accessed 25 Apr 2016.

10. Bolgatanga Municipal Health Directorate: Annual report. 2015.

11. Cheesbrough M. District laboratory practice in tropical countries. Part II. Cambridge: Cambridge university press; 2006. p. 295-8.

12. Salacinski AJ, Alford M, Drevets K, Hart S, Hunt BE. Validity and reliability of a glucometer against industry reference standards. J Diabetes Sci Technol. 2014;8(1):95-9.

13. Rajendran R, Rayman G. Point-of-care blood glucose testing for diabetes care in hospitalized patients an evidence-based review. J Diabetes Sci Technol. 2014;8(6):1081-90.

14. Ginsberg BH. Factors affecting blood glucose monitoring: sources of errors in measurement. J Diabetes Sci Technol. 2009;3(4):903-13.

15. Shete $\mathrm{S}$, Khan $\mathrm{H}$, Siddiqui AM, Shinde A. A comparative study of venous and capillary blood glucose levels by semi auto analyser and glucometer. Int J Recent Trends Sci Technol. 2016;1 (19):46-8.

16. Patel N, Patel K. A comparative study of venous and capillary blood glucose levels by different method. GCSMC J Med Sci. 2015;4(1):53-6.

17. Baig A, Siddiqui I, Jabbar A, Azam IS, Sabir S, Alam S, Ghani F. Comparison between bedside testing of blood glucose by glucometer vs. centralized testing in tertiary health care hospital. J Ayub Med Coll Abbottabad. 2007;19(3):25-9.

18. Sudan K. Comparison between glucometer and chemical analyzer for measuring blood glucose of diabetic patients. Int J Curr Res. 2014;6(5):6610-3.

19. Bimenya GS, Nzarubara GR, Kiconco J, Sabuni S, Byarugaba W. The accuracy of self-monitoring blood glucose meter systems in Kampala Uganda. Afr Health Sci. 2003;3(1):23-32.

20. Corstjens AM, Ligtenberg JJ, van der Horst IC, Spanjersberg R, Lind JS, Tulleken JE, Meertens JH, Zijlstra JG. Accuracy and feasibility of point-ofcare and continuous blood glucose analysis in critically ill ICU patients. Crit Care. 2006:10(15):R135.

21. MostafaGharehbaghi M, Ghergherehchi R. Comparison of diagnostic value of blood glucose meter with that of laboratory method in neonatal hypoglycemia. J Guilan Univ Med Sci. 2016;25(97):106-12.

22. American Diabetes Association. Standards of Medical Care in Diabetes-2017. Diabetes Care. 2017;40(1):S1-135.

23. Tape TG. The Area Under an ROC Curve. http://gim.unmc.edu/dxtests/ roc3.htm. Accessed 26 July 2017.

\section{Submit your next manuscript to BioMed Central and we will help you at every step:}

- We accept pre-submission inquiries

- Our selector tool helps you to find the most relevant journal

- We provide round the clock customer support

- Convenient online submission

- Thorough peer review

- Inclusion in PubMed and all major indexing services

- Maximum visibility for your research

Submit your manuscript at www.biomedcentral.com/submit 